\title{
Hepatotoxicity Secondary to A Drug to Lose Weight, "Orlistat": to take into Account as a Differential Diagnosis
}

Nancy Yaneth Angulo Castañeda*, Paula Andrea Castaño Arias

Medical Specialist in Clinical Toxicology of the IPS Universitaria Clinica Leon XIII, Calle 69 No 51C 24, Medellín, Antioquia, Colombia

DOI: $\underline{10.36347 / \text { sajp.2020.v09i02.007 }}$

| Received: 06.02.2020 | Accepted: 13.02.2020 | Published: 22.02 .2020

*Corresponding author: Nancy Yaneth Angulo Castañeda

\section{Abstract}

Obesity is a chronic disease, it is the result of multiple causes, which is why medications have now appeared for treatment, and some have been withdrawn due to serious adverse events; In Colombia there are two drugs approved with the indication of obesity. These are: orlistat and liraglutide. We present the clinical case of a 78-year-old patient with a history of obesity and hypertriglyceridemia, who started with cholestasis and renal failure, where when doing the clinical analysis, rule out organic causes and herbal toxicity; It was concluded with the clinical, biopsy and analysis of adverse reactions that the hepatotoxicity was given by orlistat, which was started 3 months before, after suspending she present an initial increase in transaminases with subsequent good clinical and paraclinical evolution, both hepatic and renal.

Keywords: Anti-obesity drugs, orlistat, hepatotoxicity, jaundice, obesity.

Copyright @ 2020: This is an open-access article distributed under the terms of the Creative Commons Attribution license which permits unrestricted use, distribution, and reproduction in any medium for non-commercial use (NonCommercial, or CC-BY-NC) provided the original author and source are credited.

\section{INTRODUCTION}

Obesity is a chronic disease, of multifactorial origin, since 1980 the population with this disease has doubled, according to WHO in 2014, 39\% of adults were overweight and $13 \%$ were obese [1]; The multiple investigations conclude that exercise and adequate food remain the most cost-effective and safe measures to treat this pathology. In pharmacological attempts to improve this condition, products have been found, but unfortunately most of them have brought serious adverse effects, which had to the withdrawal from the market; some examples are: In the 50s, amphetamine derivatives produced increased cardiovascular risk and dependence; in the 1990s, phentermine and fenfluramine were used, which in 1997 was withdrawn from the market due to a marked increase in the risk of pulmonary hypertension (up to 23 times higher when used for more than 3 months), and due to valvulopathy, possibly caused secondary to the increase Serotonin labeling [2], sibutramine, a dual monoamine reuptake inhibitor (norepinephrine-serotonin) that also reduced the desire to eat calories and increased energy expenditure, was also introduced to the market in the 1990s , however, in 2010 the EMA (European Medicines Agency) suspended the marketing authorization due to increased cardiovascular risk; in 2006 the EMA approved the use of rimonabant, an antagonist of the CB1 endocannabinoid receptor, which decreased appetite, however in 2008 due to reports of psychiatric problems, (depression and suicide) its marketing was suspended [3]; Currently in Colombia there are 2 medications approved by the national regulatory entity (INVIMA) for the treatment of obesity that are liraglutide and orlistat (which we will emphasize), it was approved by the FDA since 1998; it is a tetrahydrolipostatin, which is produced by the microorganism Streptomyces toxytricini that has a potent inhibitory effect of pancreatic and gastric lipase [4]; in Colombia it is available for prescription as $60 \mathrm{mg}$ and $120 \mathrm{mg}$ capsules, the usual dose is $120 \mathrm{mg}$ every 8 hours, 1 hour before each meal; when taken with meals Orlistat inhibits the digestion of ingested fat, thereby decreasing its absorption and thus reducing the amount of calories absorbed; its main adverse effects are due to the decrease in fat absorption, the most frequent are gastrointestinal symptoms: diarrhea, flatulence, abdominal pain, dyspepsia, steatorrhea and even fecal incontinence; when high fat meals are consumed, adverse effects are increased.

Orlistat's systemic absorption is at least less than $5 \%$, with undetectable blood concentrations or less than $4 \mathrm{ng} / \mathrm{mL}$ (too little to inhibit serum lipase activities), so systemic adverse effects were not expected [5], however, after marketing, there have been several reports of hepatotoxicity, from mild to severe 
that have required liver transplantation and / or death, and some cases of nephrotoxicity, which has led regulatory agencies to conduct a larger analysis. . In the reviews of hepatotoxicity due to orlistat, the alteration of liver function is mainly persistent between 2 to 12 weeks of starting orlistat, being twice the risk in this period, compared to other follow-up periods [6]. The predominant pattern is that of serum enzyme elevations, hepatocellular pattern; some of these cases have been severe, with signs of liver failure and progression to death or need for liver transplantation [5]. In the case reports, the hypersensitivity characteristics have not been prominent and the autoimmune markers have been absent, so it is considered unlikely to be associated with a hypersensitivity reaction. Regarding the frequency of hepatotoxicity due to orlistat, it is classified as rare (less than $1 \%$ ); but due to its severity it must be kept in mind and follow up properly; as is the possibility of renal failure, which may be associated with hyperoxaluria and oxalate nephropathy; and which is more frequent in patients with underlying chronic kidney disease and / or hypovolemia [7].

\section{CASE REPORT}

A 78-year-old female patient, who entered the León XIII IPS University Clinic (Hospital of high complexity Medellín, Colombia), for presenting a 5week of evolution of intense pruritus, associated with jaundice, coluria, acolia, nausea, mallet general and hyporexia; as important antecedents he has parkinson's disease, stable coronary disease, arterial hypertension, hypothyroidism, type 2 diabetes without insulin required, androgenic alopecia, grade II obesity, hypertriglyceridemia, open cholecystectomy about 40 years ago; On an outpatient basis he received the following medication: topical scalp minoxidil until one month ago, metformin $850 \mathrm{mg} \times 2$, glibenclamide $5 \mathrm{mg}$ $\mathrm{x} 1$, levothyroxine $100 \mathrm{mcg} \mathrm{x} 1$, ASA $100 \mathrm{mg} \mathrm{x} 1$, furosemide $40 \mathrm{mg}$ x1, enalapril $20 \mathrm{mg} \quad \mathrm{x} 2$, hydrochlorothiazide $25 \mathrm{mg} \times 1$, amlodipine $5 \mathrm{mg} \mathrm{x} 1$, metoprolol $50 \mathrm{mg} \times 2$ all these medications for more than 5 years, unchanged and orlistat $120 \mathrm{mg} \times 2$ for 3 months; Natural medicines received: Ego, omnilife drink, silymarin, the latter, the last to take after starting with the symptoms of cholestasis.

At admission of the icteric patient institution, hemodynamically stable, without fever; she was hospitalized for surgery to rule out recurrent choledocolithiasis vs obstructive malignant lesion of the bile duct;
Colangioresonance was performed without evidence of these and without indication of surgical treatment;

but as it continued with an increase in transaminases and progression of renal failure, ortistat was suspended and extension studies were carried out by internal medicine, to rule out viral, autoimmune and / or deposition causes, which were negative (see laboratory table) only slight elevation of the copper was evidenced but in biopsy with coloration for negative copper and also in the uroanalysis the presence of oxalates in the sediment was ruled out.

The patient was hospitalized for 13 days, while all extension studies were performed to verify and rule out possible causes.

Ultrasound showed mild hepatic steatosis and surgical absence of gallbladder without other abnormalities.

In simple magnetic resonance imaging there is an alteration in liver morphology due to atrophic postsurgical changes of the right hepatic lobe with the absence of segments VI and VII and part of V and also signs of acute nephropathy.

Liver biopsy showed morphological changes that favor drug toxicity, with portal spaces expanded by mononuclear inflammatory infiltrate and edema; in the parenchyma marked ballooning (edema) of hepatocytes, some with rare rarefaction of their cytoplasm, cytoplasmic cholestasis and binucleation. In addition, canalicular cholestasis was observed that involves all areas and in Kupffer cells small foci of hepatocyte necrosis with granuloma formation by macrophages and lymphocytes. There were no multinucleated giant cells, no caseification necrosis (See Figure-1).

The colorations showed moderate portal fibrosis, but preserved reticular architecture; fungal and mycobacterial infections, toxicity from copper or iron deposits were ruled out and with the positive PAS that together with macrophages indicate that liver injury is recent.

The patient progressively improved until discharge; with subsequent review by hepatology with paraclinics at 3 months post-hospitalization, with complete recovery of liver and kidney function (See Table-1). 

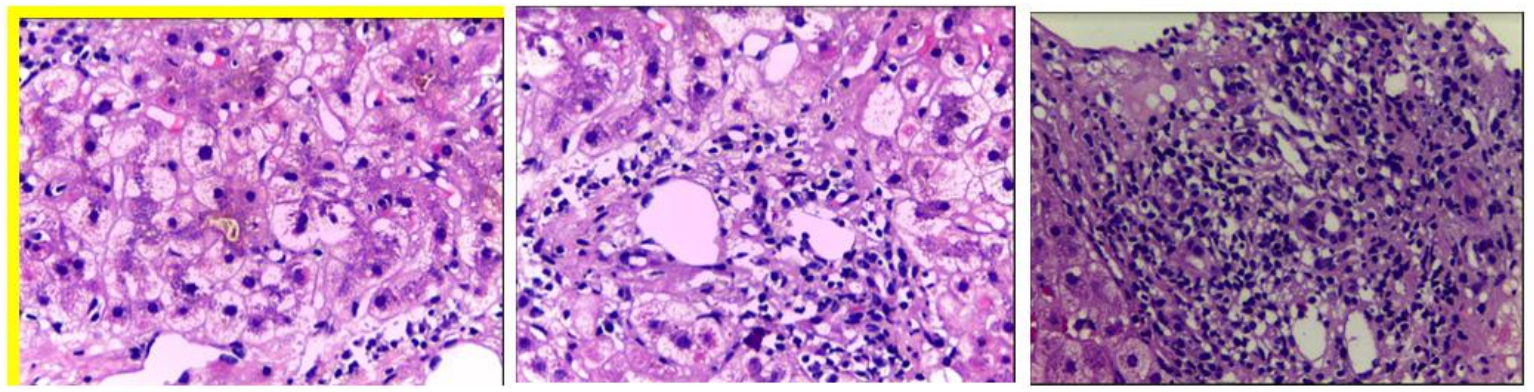

Fig-1: Pathology of liver biopsy

Table-1: Evolution of paraclinics (taken from the clinical history and the paraclinics brought by the patient)

\begin{tabular}{|c|c|c|c|c|}
\hline Paraclinicals & $\begin{array}{l}\text { Outpatient } \\
\text { prior } \\
\text { paraclinics }\end{array}$ & Day 1 & Day 5 & $\begin{array}{l}3 \text { months post } \\
\text { hospital } \\
\text { discharge }\end{array}$ \\
\hline Blood urea nitrogen & & 74,4 & 22,5 & \\
\hline Creatinine & 1,13 & 4,91 & 1,85 & 1,27 \\
\hline Aspartate aminotransferase AST & 223,2 & & 145 & 22,3 \\
\hline Alanine aminotransferase ALT & 145 & & 135 & 15,4 \\
\hline Total bilirubin & 8 & 6,34 & 13,73 & 0,73 \\
\hline Direct bilirubin & 4,62 & 4,68 & 10,39 & 0,19 \\
\hline Indirect bilirubin & 3,38 & 1,66 & 3,34 & 0,54 \\
\hline Alkaline phosphatase & & 491 & 7,55 & 216 \\
\hline Gammaglutamyl transferase GGT & & 1725 & & 30 \\
\hline Prothrombin time / Thromboplastin time & & $16,2 / 31,5$ & $16,7 / 33,1$ & \\
\hline INR & & 1,13 & 1,17 & \\
\hline \multicolumn{5}{|l|}{ Calcium / Phosphorus } \\
\hline C-reactive protein & & 0,45 & & \\
\hline Leukocytes & & 10080 & & \\
\hline Hemoglobin / Hematocrit & & $13,5 / 39,9$ & & \\
\hline Neutrophils & & 6170 & & \\
\hline Eosinophils & & 570 & & \\
\hline Platelets & & 252000 & & \\
\hline PTH paratohormone intact & & 137,7 & & \\
\hline TSH & & 0,047 & & \\
\hline Glycosylated hemoglobin & & 7,1 & & \\
\hline Antigen Ca19 9 & & 8,41 & & \\
\hline Alphafetoprotein & & $<1,3$ & & \\
\hline Ferritin & & 1209 & & \\
\hline Total iron & & 148 & & \\
\hline Transferrin saturation percentage & & 74 & & \\
\hline Copper & & 63,18 & & \\
\hline Ceruloplasmin & & 94,5 & & \\
\hline Antinuclear antibodies & & Negative & & 1,17 \\
\hline Smooth Antimuscle Antibodies & & 1:40 Positive & & \\
\hline mitochondria antibodies & & Negative & & \\
\hline Immunoglobulin $\mathrm{G}$ & & 998 & & \\
\hline Hepatitis A IgM antibodies & & 0,25 & & \\
\hline Hepatitis B surface antigen & & $<0,1$ & & \\
\hline Hepatitis B total central antibodies & & $<0,007$ & & \\
\hline Hepatitis $\mathrm{C}$ antibodies & & $<0,02$ & & \\
\hline Presumptive HIV 1 and 2 & & 0,225 & & \\
\hline
\end{tabular}

\section{DISCUSSION}

The alteration in liver function is a frequent cause of medical consultation, where hepatotoxicity by traditional and herbal medicines has had a significant increase, representing at this time $10 \%$ of the causes of liver failure worldwide, so what a differential diagnosis to consider is. Among the predisposing factors to present hepatotoxicity are: alcohol consumption, advanced age, genetic factors (polymorphisms, variants in CYP450 isoenzymes, slow acetylators), gender 
(female), diet, pregnancy, body mass index (BMI)), liver disease and diseases that intervene with the pharmacodynamics of medications such as kidney or liver [8].

There are 3 defined hepatotoxicity patterns: cholestatic, hepatocellular and mixed. The first is characterized by an elevation of alkaline phosphatase (AF) 2 times greater than the normal upper limit and / or a reaction between alanine aminotransferase (ALT) / alkaline phosphatase (FA) less than or equal to 2 . The hepatocellular pattern is defined as ALT 3 times greater than the normal upper limit and / or an ALT / FA ratio greater than 5; and the mixed pattern is ALT 2 times higher than the normal upper limit, with a ratio between ALT /FA between 2 and 5 [9]. It should be remembered that the criteria for suspending a drug due to hepatotoxicity are ALT greater than 3 times the normal upper limit (LSN) in symptomatic patients; or ALT is greater than 5 times LSN if there are no symptoms and when ALT is greater than 3 times LSN with total bilirubin 2 times LSN [10].

In the case of the patient we presented, she had several predisposing factors for hepatotoxicity: exposure to herbal products, obesity, female gender, polymedication; for the analysis of hepatotoxicaad, frequent causes of jaundice, renal impairment and hepatic impairment should be frequently ruled out. As initial causes to rule out, there was recurrent choledocolithiasis or obstructive malignant lesion, which was ruled out by means of colangioresonance; Others are autoimmune, infectious, obstructive, metabolic and deposit causes, which according to the results of paraclinics were ruled out, and as a last cause hepatotoxicity was suspected, mainly given by the patient's report of having taken "silymarin and Ego" natural remedies. However, when making the chronological history of the onset of symptoms and medications, it is evident that the patient takes natural remedies after starting with the icteric picture; as for the medications that they received chronically for their AHT and their hypothyroidism without changes in dose or medications in the last 2 years; Orlistat was the only dug that had recently begun, so that due to plausible temporal relationship and according to WHO algorithms to evaluate drug causality, it is considered possible hepatotoxicity due to orlistat, serious, not avoidable, type B; and by the Naranjo algorithm it is also classified as possible by 4 points. It was observed that although the orlistat was discontinued the increase in transaminases continue; which is described in other reports of severe hepatotoxicity due to orlistat where progression continues several weeks after stopping the medication [5]; The diagnostic suspicion is confirmed by biopsy and the evolution of the patient to total improvement when the medication is discontinued.
In our case, the patient also performed acute renal failure AKI III, with a previous creatinine of 1.13 extrahospital, when admission was 4.9 and progress up to 5.25 (correlating with the increase in transaminases), without requiring renal replacement therapy, presenting improvement after liver function improvement; Although orlistat has also been associated with nephrotoxicity, it is caused by oxalates, which were not present in the patient's urine sediment; As liver function improved, renal function also improved, showing a total improvement in outpatient follow-up at 3 months, which is why the alteration is thought to have been more associated with hepatic alteration, than directly orlistat.

As reviewed in the literature and in the case we present, we do not find that hepatotoxicity due to orlistat is due to hypersensitivity (there is no evidence of eosinophilia or other hypersensitivity alterations), rather it may be caused by direct toxicity or idiosyncrasy of the patient, although It is uncommon, it can lead to death or liver transplantation, so it is important to take into account and follow up mainly in the first 3 months of starting the medication.

\section{CONCLUSION}

The maximum peak of hepatotoxicity and nephrotoxicity due to orlistat occurs in the first 3 months after starting the drug with a rare frequency of less than $1 \%$. To reduce this risk, avoid the prescription of orlistat in patients with hepatopathy or previous nephropathy, perform paraclinics of hepatic and renal function with uroanalysis (to verify that they do not have oxalates) in three measurements: prior to starting the medication, one month after 3 months after the orlistat started; in addition, warning signs (symptoms of hepatic or renal dysfunction) should be given to stimulate early consultation, give recommendations for adequate hydration, since hypovolemia increases the risk of oxalate nephrotoxicity; and suspend in cases where hepatotoxicity is suspected and if they already presented it, never re-expose.

\section{REFERENCES}

1. Obesidad y sobrepeso [Internet]. Who.int. 2020 [cited 27 January 2020]. Available from: http://www.who.int/mediacentre/factsheets/fs311/e s/

2. Anon, (2020). [online] Available at: https://www.icf.uab.cat/assets/pdf/productes/bg/es/ bg105.97e.pdf [Accessed 27 Jan. 2020].

3. Rodgers R, Tschop M, Wilding J. Anti-obesity drugs: past, present and future. Disease Models \& Mechanisms. 2012;5(5):621-626.

4. Ransac S, Gargouri Y, Moreau H, Verger R. Inactivation of pancreatic and gastric lipases by tetrahydrolipstatin and alkyl-dithio-5-(2nitrobenzoic acid). A kinetic study with 1,2didecanoyl-sn-glycerol monolayers. European Journal of Biochemistry. 1991;202(2):395-400. 
5. Orlistat [Internet]. Ncbi.nlm.nih.gov. 2020 [cited 27 January 2020]. Available from: https://www.ncbi.nlm.nih.gov/books/NBK548898/

6. Douglas I, Langham J, Bhaskaran K, Brauer R, Smeeth L. Orlistat and the risk of acute liver injury: self controlled case series study in UK Clinical Practice Research Datalink. BMJ. 2013;346(apr12 1): 1936-1936.

7. [Internet]. Ema.europa.eu. 2020 [cited 27 January 2020]. Available from: http://www.ema.europa.eu/docs/es_ES/document_ library/EPAR_-

_Product_Information/human/000154/WC500058 428.pdf
8. Restrepo JC, Muñoz JF, Correa G, Zuleta J, Londoño M, Botero A, Osorio G, Sepúlveda ME, Yepes NL. Hepatotoxicity detected in a fourthlevel hospital at the city of Medellín. Acta Medica Colombiana. 2008 Dec;33(4):261-7. Available from:

http://www.scielo.org.co/scielo.php?script=sci_artt ext\&pid=S0120-24482008000400002\&lng=en.

9. Morales Maya L, Vélez López N, Muñoz Maya O. Hepatotoxicidad: patrón colestásico inducido por fármacos. Revista Colombiana de Gastroenterología. 2016;31(1):36.

10. Aguayo CM, Rodríguez DJ. Hígado y terapia antituberculosa. Revista chilena de enfermedades respiratorias. 2011;27(1):53-57. 